\title{
Sensitizing students to information security and privacy awareness with analogue gamification
}

\author{
Margit Scholl*
}

\section{Zusammenfassung}

Viele Studien und Untersuchungen im Bereich der Informationssicherheit zeigen einen nachlässigen Umgang mit sensiblen Daten und ein unzureichendes Bewusstsein der Menschen für die Informationssicherheit. Trotz der zunehmenden Digitalisierung, die die Gesellschaft insgesamt stark beeinflusst, neigen wir dazu, den damit verbundenen Risiken nicht genügend Aufmerksamkeit zu schenken. Sensibilisierung der Menschen ist nötig und soll zu ihren Verhaltensänderungen in der IT-Sicherheit führen. Untersuchungen zeigen jedoch, dass der bloße Wissenstransfer nicht ausreicht, um Verhaltensänderungen zu bewirken. Vielmehr ist ein systemischer Ansatz hilfreich, der durch analoges, spielbasiertes Lernen die notwendige Emotionalisierung für Austausche von Erfahrung und eine Reflexion der Menschen herbeiführen kann. Digitales, spielbasiertes Lernen in der IT-Sicherheit sollte ebenfalls die Emotionalisierung der Menschen adressieren.

Schlüsselwörter: Digitalisierung, digitale Transformation, IT-Sicherheit, Datenschutz, Sensibilisierung für Informationssicherheit, spielbasiertes Lernen und Simulation

\begin{abstract}
Many studies and investigations in the area of information security reveal a careless handling of sensitive data and insufficient information security awareness. Despite increasing digitization, which has a huge impact on society as a whole, we tend not to pay enough attention to the risks associated with it. But research shows that the mere transfer of knowledge is not enough to cause behavioural changes. Rather, a systemic approach that can bring about the necessary emotionalization and reflection through analogue game-based learning is helpful.
\end{abstract}

Keywords: Digitization, digital transformation, information security, privacy, information security awareness, information security awareness trainings, game-based learning, simulation games, security sensitization

\section{Introduction}

Digitalization aims to modernize our society and keep the world of work competitive in the future. The associated use of cutting-edge digital information and communication technology (ICT) has changed institutional work structures, rationalizing old jobs and creating new ones, not only changing communications and social behaviour, creating virtual communities, and so on but also creating a digital divide (Gesellschaft für Informatik 2018: 8). As a technical university, we are faced with the question of how students can be prepared for non-technical study programmes for the new age and sensitized to information security.
Moreover, as the German Informatics Society (GI) points out in article 7 of its Ethical Guidelines, the design and implementation of ICT systems, including any control and monitoring techniques, should be combined with user involvement (Gesellschaft für Informatik 2018: 6). More specifically, the personal data that is constantly being collected is "a gold donkey for cyber criminals" (Kaspersky Lab 2018).

The use of new media and social networks has become a matter of course for many people and it is impossible to forget these in our everyday lives. Against this background, the General Data Protection Regulation (GDPR) of the European Union (EU) and the work of data protection officers is becoming increasingly important (Bundesakademie für öffentliche Verwaltung im Bundesministerium des Innern 2018). Privacy covers the protection of personality rights and consumer protection. However, according to a recent survey published by Thales, around one-third of the consumers surveyed in Germany (35 per cent) said they do not trust anyone when it comes to personal data protection, and in terms of digital privacy, 45 per cent of respondents believe that businesses are largely indifferent to digital privacy (Thales 2018).

Digitization requires us to live with digital threats that can damage key assets such as our wealth, knowledge, 
or health (Bundesakademie für öffentliche Verwaltung im Bundesministerium des Innern 2016). Vulnerabilities are everywhere: the gaps in the security of a system or software or of an organization that can be exploited by specific and real attacks. In many cases attempts have been made to use technology to close these security loopholes. But the well-informed and sensitized individual remains an important element in defending against attacks (Dark 2006). In addition, there are forms of attack such as social engineering (SE) that are aimed directly at people, using false pretences to obtain important information: such targets are increasingly focused on in the runup to technical cyberattacks. In SE attacks, the individual is, depending on the perspective you take, both perpetrator and victim (Haucke \& Pokoyski 2018: 4): perpetrator, in that they have committed a mistake that violated the security policy of their own organization, and victim, in that they have disclosed such information as a result of deception and manipulation.

New safeguards must be implemented in the form of continuous information security (IS) and legally compliant data protection. IS and IT security incidents can have far-reaching, cost-intensive repercussions that harm business or interfere with the performance of tasks (Bundesamt für Sicherheit in der Informationstechnologie 2008). The digital transformation (DT) is not only chang ing all the business processes in the individual institutions but is also having an increasing impact on our entire (knowledge) society. DT is an ongoing process of modifying people's communication and their behaviour when dealing with modern technology. According to the Federal Office for Information Security in Germany (BSI), all employees need to know the security objectives of the institution, understand the security measures, and be willing to support them effectively. For this they must be trained. In particular, they must know what is expected of them in terms of IS and how they should respond in security-critical situations (Bundesamt für Sicherheit in der Informationstechnologie 2018).

Section 2 summarizes the main scientific knowledge relating to the human side of IS and information security awareness trainings (ISAT) as well as some of the ethical responsibilities of informatics. Section 3 discusses several examples of analogue game-based learning scenarios for practice, because Serious Games have great potential in the field of ISAT. Section 4 outlines the conclusions of our experience with students and looks at the prospects for further projects.

\section{The Human Side of Information Security and Ethics}

Information security (IS) and information technology (IT) are about more than technology (Kruger et al. 2007). ICT systems involve human actors, yet users do not always behave as they should (Aytes \& Connolly 2004). Nevertheless, people should not necessarily be labelled the weakest link in the chain of vulnerability when many studies show that there are often basic IS deficiencies in the institutions themselves. The negative characterization of people in the area of IS should now be reconsidered (Scholl et al. 2018).

Threats and vulnerabilities need to be understood (Bundesamt für Sicherheit in der Informationstechnologie 2018). Well-informed and sensitized people have developed an awareness of information security (ISA), know appropriate rules for dealing with (sensitive) information, and accept the organizational regulations. Information Security Awareness Trainings (ISAT) are necessary. However, Tsohou et al. (2012) conclude from current global security surveys that ISAT is currently not working. The reasons for this are described in the scientific literature-in terms, for example, of a more "technocratic" view of risk communication (Stewart \& Lacey 2012) and/or as long lists of commandments and prohibitions (Kirlappos et al. 2013). In addition, adhering to a safety culture cannot be achieved through training that merely aims to eliminate security vulnerabilities (Fagade \& Tryfonas 2016).

ISAT needs a "methodology 3.0" (Scholl et al. 2016), which, in addition to imparting knowledge of the abstract topic, focuses primarily on the emotional involvement of humans and on a collaborative team process as a key component required for the development of consciousness. It is important to distinguish between sensitization as a first step towards more awareness of information security and in-depth training. Psychological research has shown that, in addition to the classical theoretical approach of knowledge transfer and the marketing-oriented approach of emotionalizing, a systemic approach to team-based communication is required (Pokoyski 2009, Khan et al. 2011, Beyer et al. 2015) to successfully train people in the field of information security.

The DT that accompanies digitization requires new competencies, skills that extend beyond the realms of information technology. It is not enough for programming lessons to be implemented from Year Three on. Rather, the constantly changing technologies and their impact on society, the extremely abstract topics of computer science, and the complex relationships of information security have to be made clear and comprehensible for, and together with, the people involved. Here, politics and computer science also have an ethical responsibility in relation to digital transformation within society as a whole. The Society of Informatics' (GI) Ethics Guidelines seek to do this by expecting $\mathrm{Gl}$ members to extend their personal expertise to understand the rights and interests of different stakeholders (Gesellschaft für Informatik 2018: 4). The willingness to participate in interdisciplinary discussions and the process of informing learners about their individual and shared responsibilities and their own position as role models are just as much part of this as the realization that acting together requires both individual and group reflection (Gesellschaft für Informatik 2018: 4ff., 14).

Serious games are an interesting tool in the process of sensitization - in particular with regard to the emotionalizing necessary for the development of an information security awareness and the concomitant exchange of experience, expectations, and reflections. Our experiences in research and teaching are discussed in the next section. 


\section{Analogue Gamification for a Digitally Based Life}

Game-based learning is receiving increasing recognition as an effective teaching and learning method that improves motivation and triggers behavioural changes (Bösche \& Kattner 2011). It is described as an entertaining and motivating form of learning (Albert \& Linek 2009). Another term that is often used in this context is "gamification". Serious Games have great potential to make valuable contributions to socially relevant areas such as education, health, and society (Göbel 2017, Institute of Play 2018). Gamification implies the application of game elements in non-playful contexts such as work processes or teaching (Huotari \& Hamari 2017). Some of the classic game elements are points, leader boards, game results, levels, challenges, rewards (e.g. awards), progress indicators (Codish \& Ravid 2017), competitions, etc. Based on what we have learned at the Technical University of Applied Sciences Wildau (TH Wildau), gamification will become even more effective, the more realistic the learning scenarios are in real life. Simulation games (Planspiele), which can be time-consuming and complex in terms of content, are one possible manifestation of gamification. In simulation games, participants are supposed to gain the most realistic and practice-oriented insight into specific problems and relationships by simulating a practical situation and through joint reflection, making their own decisions and experiencing the consequences of their actions (see http://methodenpool.unikoeln.de/planspiel/frameset_planspiel. html).

ISA learning methods should clarify threats, vulnerabilities, attacks, and possible damage as well as the main values of IS and data protection. The three basic values are confidentiality, integrity, and availability. Additional values include authentication, commitment, and reliability (Bundesamt für Sicherheit in der Informationstechnologie 2008). In many organizations, ISA and the training of relevant competences (ISAT) are often limited to knowledge-transfer measures. Based on psychologically based research
(Pokoyski 2009, Helisch \& Pokoyski 2009, Haucke \& Pokoyski 2018) on creating lasting sensitization and promoting security-related behaviours (Albrechtsen 2007, Helisch \& Pokoyski 2009, Khan et al. 2011), the gamebased learning (GBL) methodology is becoming more important for ISA. The so-called "3.0 Systemic Approaches" of Scholl et al. (2016) were implemented as a "Security Arena" and tested with different target groups at the TH Wildau (Fuhrmann et al. 2017). Major campaigns for large companies like T-Systems, Alliance, BMW, and HP were also completed with an analogue "Security Parcours" (see https://web.eco. de/news/unterwegs-auf-dem-security-parcours/) by the firm known_sense or individually organized, as was the case with Deutsche Post (Take Aware 2018).

To raise awareness as a first step in building an individual's information security awareness and a security culture in the organization, in our experience, the game-based learning scenarios must greatly reduce the complexity of the topics to attract attention in a short time to the selected theme or problem or question. Emotionalizing must address people's specific concerns. Psychological studies (Haucke \& Pokoyski 2018) show that people need to "understand"-through emotional engagement-that they are themselves affected. Analogue GBL is especially effective as a means of stimulating motivation and should be explicitly used for ISAT, because learners can directly see the consequences of their actions and get a sense of their knowledge level in dialogue.

\subsection{Example 1: Security Arena for Different Aspects of IS}

The two-year research project SecAware4job, which was funded by the Horst Görtz Foundation from 2015 to 2017, aimed to develop, visualize, and examine as many creative learning and teaching methods as possible so that students, staff, and guests can appreciate the information security complex, and all the different facets (regulatory framework, norms and standards, protective measures) can be understood more easily (see: http:// secaware4job.wildau.biz). The themes of the analogue GBL scenarios of the "Security Arena" from the TH Wildau project "SecAware4job", which were also developed in English, include "Clear desk", "Phishing", "Password Hacking", Social Media", "Social Engineering", "Security on the Go", "Incident Management", "Internet Services \& Apps" (Fuhrmann et al. 2017, Scholl 2018).

The applied methodological framework is a learning station format (Stationenlernen) that goes back to circuit training in sports. Each learning station is presented in a playful manner and consists of a five-minute introduction to a special topic that also integrates a dialogue between participants. There follows a phase of authentic learning in which the participants as a team solve real problems from everyday (professional) life. The teams of about ten people each receive points and discuss the solution, enabling immediate learning within a maximum of five minutes. All in all, one learning station needs approximately fifteen minutes. Playing four stations in parallel as a competition, it takes only one hour to sensitize about forty people. The completion of the learning stations is the prelude to addressing a topic in greater depth, involving as many interactive methods as possible. By way of repetition, these analogue learning stations can be complemented by digital learning games in blended learning formats. In the SecAware4job project, a number of topics (for example, phishing and social engineering) were also developed as digital game versions under the creative commons licencethese can be accessed on the project website. 


\subsection{Example 2: Data Security Protection}

In addition to the learning stations from the Security Arena for Privacy, a self-contained board game for teams has been developed, which takes 30-50 minutes, depending on the luck of the dice (see Tab. 1). All the players start with fifteen data points. In the course of the game, the players are confronted with scenarios from different areas of life, which each require a decision about what information is disclosed. The decisions are made easier for the players by the specification of decision alternatives.

The players choose the alternative that best matches their real behaviour. The gameplay is influenced by event fields. These relate to decisions previously made by the players. For example, data may have been stolen by a hacker attack. Depending on how sensitive the information is, the players lose data points. However, with a bit of luck, players may also gain points based on the security measures taken (e.g. password change, deletion of Facebook profile) or through a protective measure (e.g. use of a firewall, backup). These reward and protection cards are given to the players in the "security specialist" field. Players who have lost five data points move inward. The players can rescue themselves from the penultimate circle with a lucky throw (shamrock symbol on the dice) and move back to the outside. However, anyone who reaches the innermost circle loses all their data points and thus also the game.

Tab. 1) Learning scenario, task, and goals of the game "Keep your data private. Everyday." developed in the project "SecAware4job" (Fuhrmann et al. 2017).

\begin{tabular}{|c|c|c|}
\hline Learning scenario & Learning task & Learning goals \\
\hline "Keep your data private. Everyday." & $\begin{array}{c}\text { Deal with impactful decisions relating } \\
\text { to individual and work-related IS or } \\
\text { privacy }\end{array}$ & $\begin{array}{c}\text { Explore security-relevant decisions and } \\
\text { possible consequences and } \\
\text { protective measures }\end{array}$ \\
\hline
\end{tabular}

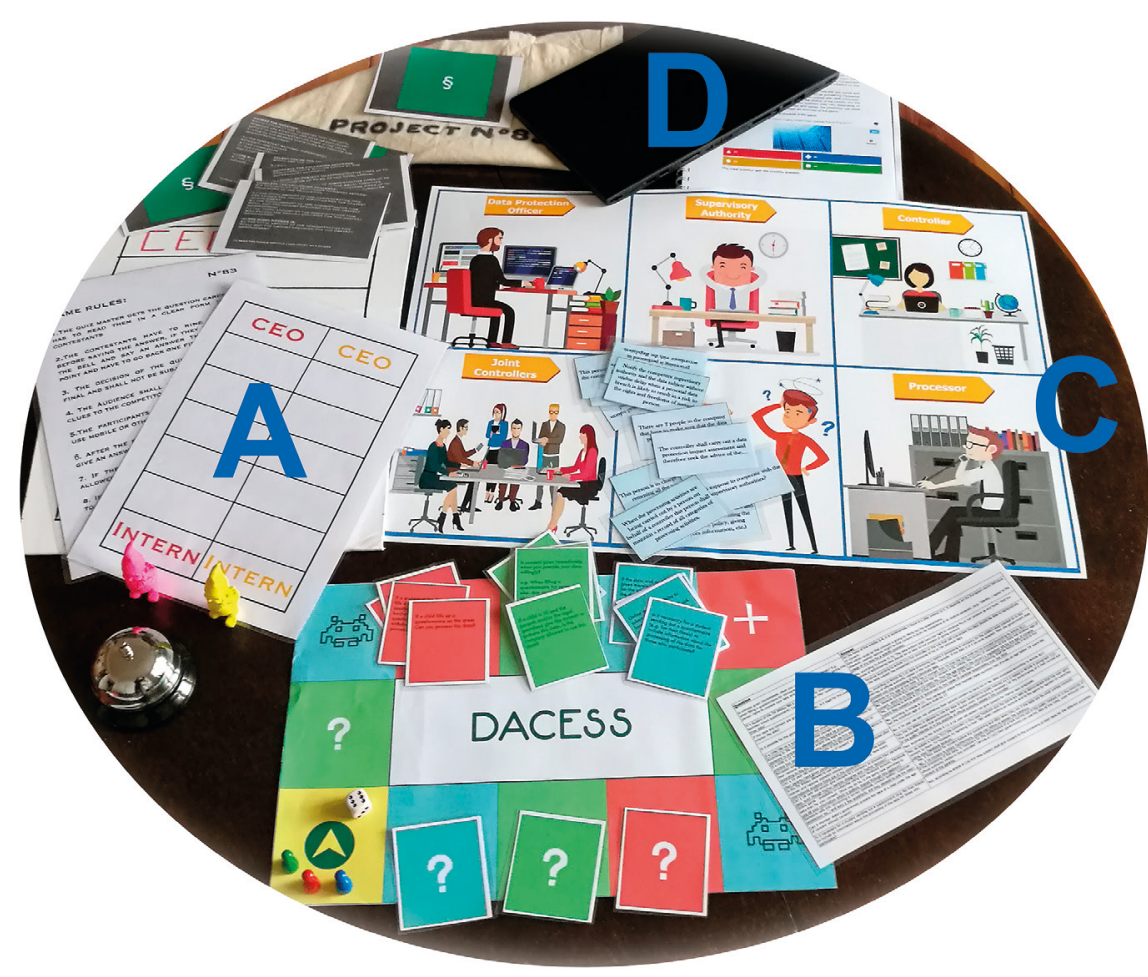

Fig. 1) Analogue game on the new EU GDPR developed by students (EMM17 in WS1718; see Scholl 2018).

\subsection{Examples 3-6: Student ideas for game-based learning of data protection}

\section{Example 3: Project No. 83}

The first student team in the European Management master's programme (EMM17) to participate in the project management course in winter semester 2017/2018 (WS1718) developed a game-based scenario called No. 83 . The task was to develop a game that would explain chapter 8 of the GDPR with emphasis on articles 83 and 84 , which deal with the general conditions for imposing administrative fines and penalties. The team needed around twelve weeks to complete the project. The game is coordinated by a quizmaster and played by two participants guided by common rules that are spelt out before the beginning of 
a question correctly. The game ends when all the question cards with the scenarios are gone. The moderator plays an important part, leading the players through the game and reading out the questions, while also ensuring the proper conduct of the game. Here are some examples of the questions involved: Is consent given immediately when you willingly provide your data? If the data and consent are only given orally, is it legal for the controller to process the data? Can a ten-year-old object to having their data processed if their parents have given consent?

\section{Example 5: Responsibilities}

Another student team developed an analogue GBL scenario for the GDPR called "Responsibilities in data protection activities" (see Fig. 1, C). The aim of this game is to extend or reinforce the knowledge acquired about data security processes and identify the responsible people in each part of the process. Playing the game relies on knowing certain things in advance. In the data protection process described in the regulation, many different players are involved-for this game, the responsibilities of five key people have to be understood: the processor, the con- troller, joint controllers, data protection officer, and the supervisory authority.

\section{Example 6: Individual repetition}

For the purposes of repetition and to monitor individual progress, simple digital GBL scenarios are also useful, e.g. the quiz app that was developed with twelve questions based on three main topics from the EU's GDPR chapter 3, art. 12-23. This will be used to explain data protection to pupils between Years 7 and 13 using smartphones or tablets (see Fig. 1, D). The EMM project team has used a free app called "Kahoot" to create the digital GBL scenario, i.e. the quiz. Using the result slide, the presenter will have the chance to explain the answers in more detail if many pupils had the wrong answer. However, digital GBL scenarios were not the focus of this paper.

\section{Example 7: e-Akte and Risk}

Management

A student team from the public administration and law course (VR15) developed an analogue game-based scenario for "e-Akte" based on current e-Government law in Germany. The game deals with files stored electron- ically in the document-management systems of public administrations - a new tool of E-Government (Fig. 2). Here, it is important that the users of this electronic medium are also familiar with and able to cope with the risks and dangers associated with e-Akte. The goal of the game is to sensitize the players (also referred to as users) to risks. Players should also learn how to assess these risks and apply appropriate measures and safety precautions. The goal is to ensure the safe and responsible use of the new e-Akte technology. It is also important to the inventors of the game that the users constructively discuss the content in order to arrive at a common solution. The aim is to create a connection that is as close to reality as possible, which players can later integrate into their daily routines. They should gain basic knowledge which they can apply in their professional activity in appropriate situations. All student product developments still need to be comprehensively tested with other student and target groups and then improved in terms of the learning scenario, complexity reduction, task formulation, and goal definition.

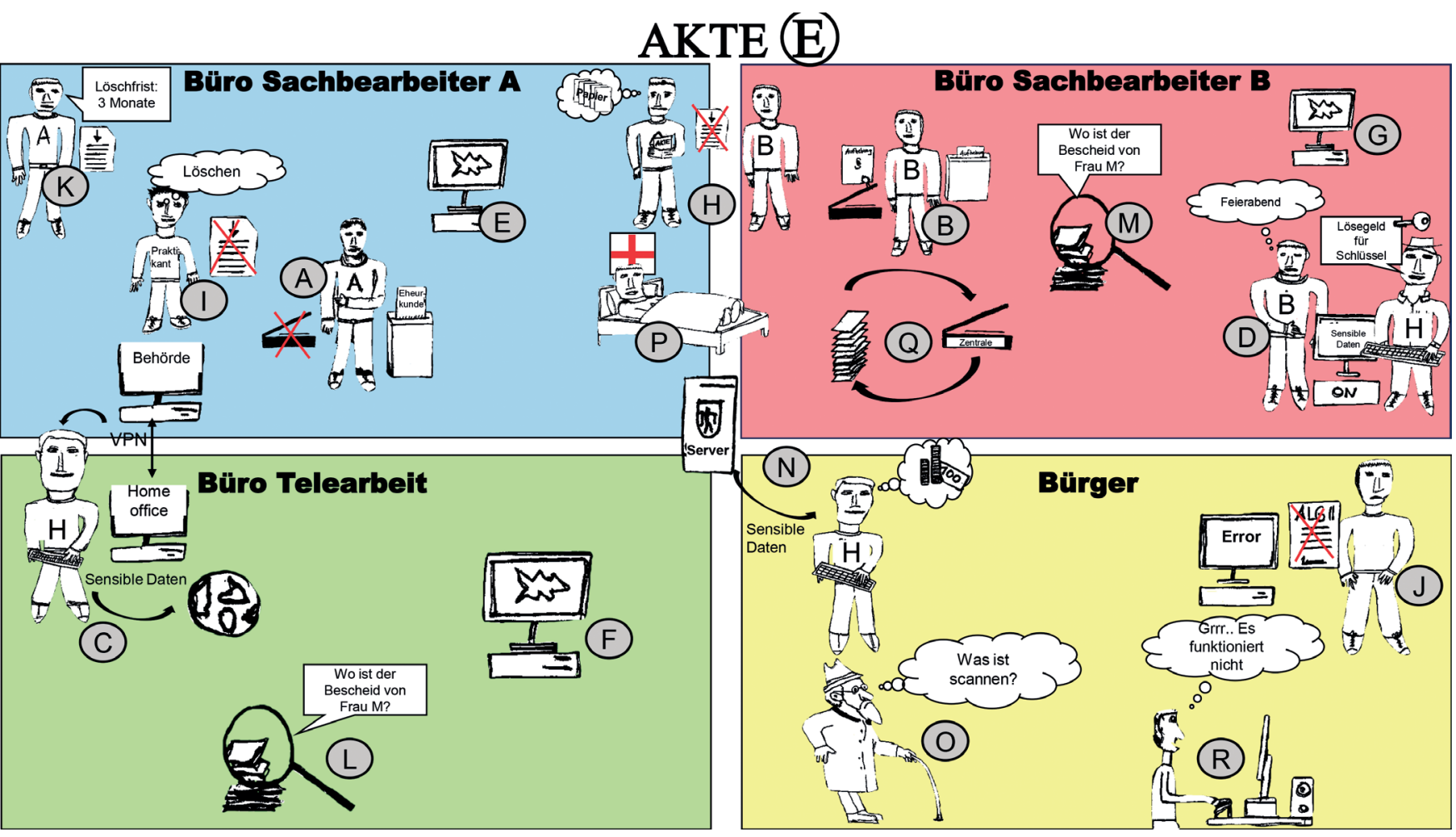

Fig. 2) Analogue game-based scenario (in German) for e-Akte and possible risks created by a VR15 student project team in WS1718. 
Emergency management is concerned with continuing business processes in emergency situations and, if necessary, rapid recovery after damage has occurred. This is also referred to as business continuity management. A first step towards understanding emergency preparedness and emergency response is the distinction of terminology. How can an emergency be distinguished from a disorder? What characterizes a crisis as compared to an emergency? What are the characteristic features of a catastrophe? What is meant by normal operation? Such questions from the BSI standard 100-4 were the starting point for the game idea "Black Out", originally developed by a student group from VR15 in WS1718 as a pilot and in the following semester by a part-time student from BFG14 (Business Administration). social engineers (see Tab. 2).
The Social Engineering Role-Playing Game aims to raise awareness of the often-unknown methods of social engineering attacks, whereby criminals use fraud and manipulation to gather sensitive information (e.g. business secrets, passwords) from companies, employees, or private individuals. Social engineers use the traits of their contact persons (also called "social impact gateways") to access sensitive information (Haucke \& Pokoyski 2018). Through the role play, participants get to know and recognize their own "gateways" (e.g. curiosity, helpfulness, stress, etc.) and how they are targeted by social engineers. The players' powers of observation are also trained to help detect incongruent behaviour in

The role-playing participants (see Fig. 4) can either take an active part and, for example, play the role of a social engineer or victim or opt for an observer

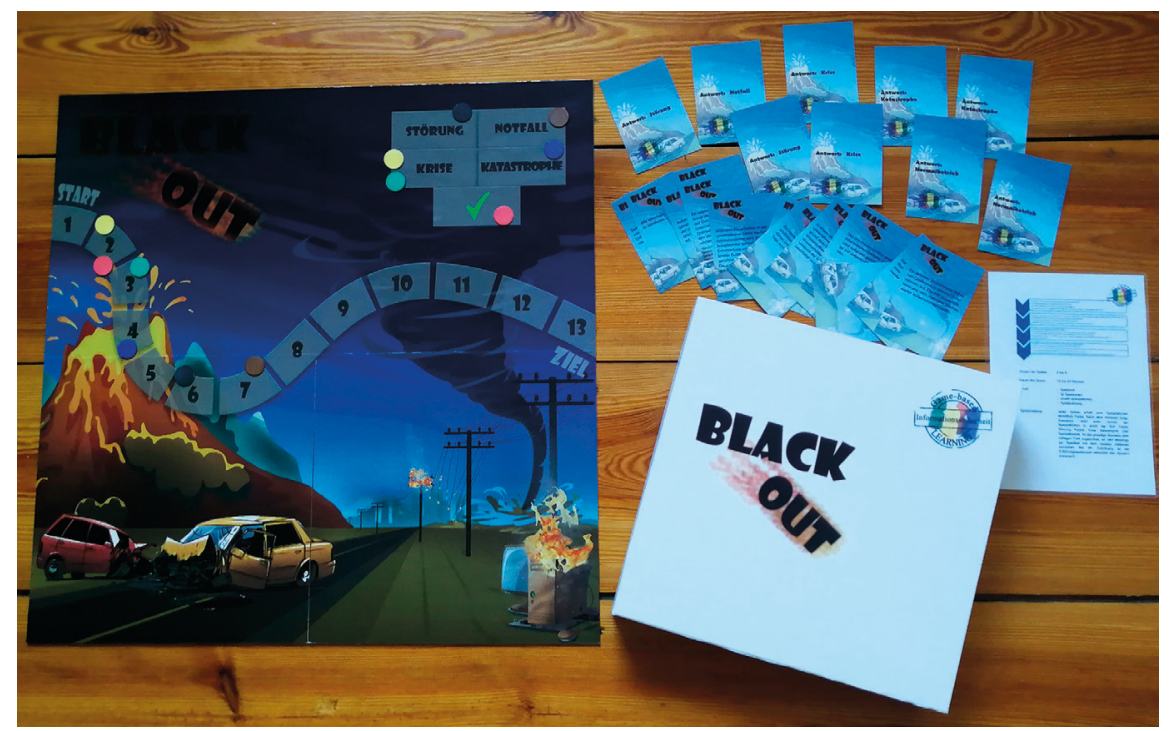

Fig. 3) An analogue game improvement (in German) by a female student of the Business Administration course (BFG14) in SoS18 relating to terms in Emergency Management. The original idea came from a student project group from the degree programme Administration and Law (VR15) in WS1718. position and try to find out as much information as possible. There are three independent rounds: the first round simulates a situation on public transport where the active players act out smartphone "quirks" (e.g. loud phone calls in public, the constant taking of photos, and posting to social media) and the people watching the game are required to identify them. In the second round, the observers witness the social engineering situation. For example, an alleged bank client tries to find out a bank employee's private address during a consultation. The task of the observing gamers is to find out the social impact gateways being played, the techniques of the social engineers, and the secret information that the social engineer is trying to obtain. In the third round, all the players are invited to enter and browse a Social Network "Placebook" to guess which social gateway the six people presented are vulnerable to. Based on this, a social engineer can choose his method for spying on sensitive information.

The active players are given cards with a role description and game tips. The observing players note their findings on a specially created website using a tablet. This allows quick and timely evaluation. Screenshots of the web page, maps, and placebook profiles are shown in Fig. 3. This game is a prototype and still in progress and requires further funding (Fuhrmann et al. 2017).

\section{Conclusion and Outlook}

The aim of this paper is to show that concepts for analogue game-based scenarios can be used to sensitize students. Within the framework of course projects, students can intensively exchange information on individual topics of information security and even develop game-based learning scenarios

Tab. 2) Learning scenario, task, and goals of the "Social Engineering Role Play" developed in the project "SecAware4job" (Fuhrmann et al. 2017).

Learning scenario

Social engineering role play
Learning task

Identify social impact gates, social engineering techniques
Learning goals

Know and internalize "social gateways" and the techniques of social engineers. Sensitize and encourage observation. 


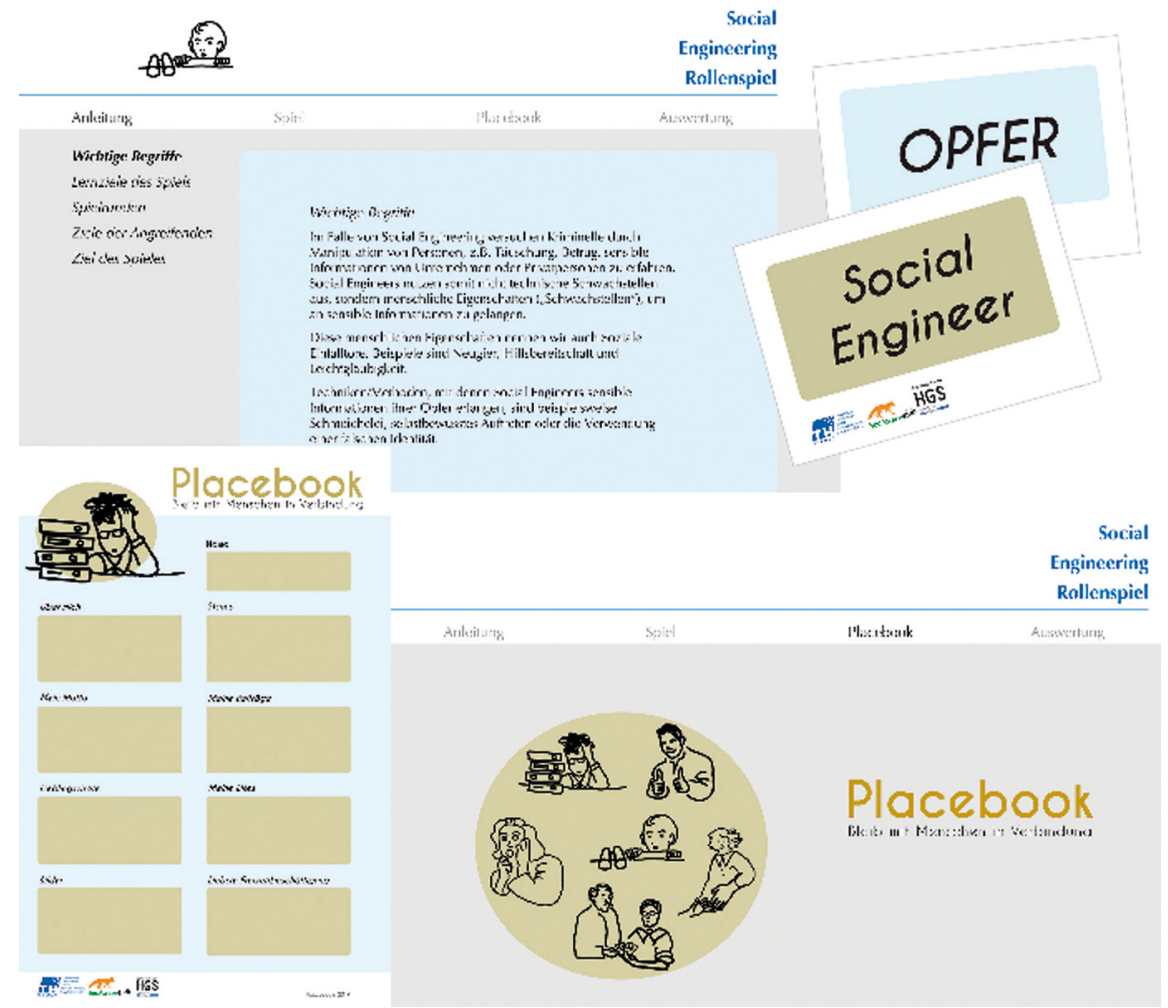

Fig. 4) Components of the social engineering role play in German developed in the project "SecAware4job" (Fuhrmann et al. 2017).

for other groups. Designing ISAT with analogue scenarios, emotionalizing, and team-based exchange-as mentioned above-is extremely important for the motivation and successful sensitization of human actors in the field of IS. Depth-psychological studies show that emotionalization and motivation are important factors in creating shortterm scenarios in real-life situations using authentic learning ( $A L$ ) and problem-based learning (PBL). Our own extensive experience with such learning materials and methods in projects and events suggests that ISA and the knowledge associated with it could be improved in almost all participants and behavioural changes triggered.

Nevertheless, there is no simple linear cause-and-effect relationship between institutional safeguards and knowledge, attitudes, and real behaviour. ISA remains a critical issue. Therefore, ISA trainings and programmes must be developed as a user-centred approach. Moreover, a clear set of IS principles needs to be identified and communicated (Kirlappos et al. 2013). Learning in IS should be developed by integrating target-oriented, interactive analogue/digital GBL scenarios and team-oriented methods as an ongoing process (Göbel 2017, Institute of Play 2018).

The research project "Gender-Sensitive Study and Vocational Orientation for the Occupation Security Specialist (Security)" aims to make the occupational field of information security better known among female students and thus to make courses of study related to computer science more attractive to young women. Through an appealing and gender-sensitive presentation of the profession of security specialist, through portraits of female role models working in the field of information security, and through an interactive and experience-oriented pilot measure, female students in the vocational orientation phase (Year 9) learn that the information security profession is very versatile (see http://www.security.wildau.biz). The two-year Security project will be funded from 2017 to 2019 by the Federal Ministry of Education and Research (BMBF).

In the current, two-year research project SecAware4school, which is once again funded by the Horst Görtz Foundation, students, teachers, and parents should be supplied with the current state of knowledge on information security issues in everyday school life at three different levels of difficulty and sensitized to the topics by using analogue and digital serious games. In addition, by 2020, pupils will be trained as youth security advisers to achieve sustainability in the use and development of game-based learning scenarios even after the project ends (see http:// secaware4school.wildau.biz). Moreover, analogue and digital serious games should be used in combination to raise awareness as part of further ongoing research projects relating to small and medium-sized enterprises. 


\section{REFERENCES}

Albert D, Linek SB (2009) Game-based learning: Gender-specific aspects of parasocial interaction and identification. In: Gómez Chova L, Martí Belenguer D, Candel Torres I (eds) INTED 2009. Proceedings. International Association of Technology, Education and Development, Valencia, ISBN: 8461275780, pp 1155-1164

Albrechtsen E (2007) A qualitative study of users' view on information security. Computers \& Security 26(4):276289. doi: 10.1016/j.cose.2006.11.004

Aytes K, Connolly T (2004) Computer Security and Risky Computing Practices. Journal of Organizational and End User Computing 16(3):22-40. doi: 10.4018/ joeuc. 2004070102

Beyer M, Ahmed S, Doerlemann K, Arnell S, Parkin S, Sasse A, Passingham N (2015) Awareness is only the first step. A framework for progressive engagement of staff in cyber security

Bösche W, Kattner F (2011) Fear of (Serious) Digital Games and Game-Based Learning? International Journal of GameBased Learning 1(3):1-15. doi: 10.4018/ijgbl.2011070101

Bundesakademie für öffentliche Verwaltung im Bundesministerium des Innern (2016) Handbuch IT-Sicherheitsbeauftragte in der öffentlichen Verwaltung.

Fortbildungslehrgang mit Zeritfikat, Brühl

Bundesakademie für öffentliche Verwaltung im Bundesministerium des Innern (2018) Handbuch Behördlicher Datenschutzbeauftragte in der Bundesverwaltung. Fortbildungslehrgang mit Zertifikat, Brühl

Bundesamt für Sicherheit in der Informationstechnologie (2018) ORP.3 Sensibilisierung und Schulung. https:// www.bsi.bund.de/DE/Themen/ITGrundschutz/ITGrund schutzKompendium/bausteine/ORP/ORP 3 Sensibilisierung_und_Schulung.html. Accessed 06 Nov 2018

Bundesamt für Sicherheit in der Informationstechnologie (2008) BSI-Standard 100-1: Information Security Management System (ISMS). https://www.bsi.bund. de/SharedDocs/Downloads/EN/BSI/Publications/BSIStandards/standard_100-1_e_pdf.pdf;jsessionid=FCA7C FAC590FCD5F4421EDB1B50A6CCE.2_cid341?_blob=publicationFile\&v=1. Accessed 12 Nov 2018

Codish D, Ravid G (2017) Gender Moderation in Gamification: Does One Size Fit All? In: Proceedings of the 50th Hawaii International Conference on System Sciences (2017). Proceedings of the Annual Hawaii International Conference on System Sciences. Hawaii International Conference on System Sciences. doi: 10.24251/HICSS.2017.244

Dark M] (2006) Security Education, Training and Awareness from a Human Performance Technology Point of View. In: Whitman ME, Mattord HJ (eds) Readings and cases in the management of information security. Thomson Course Technology, Boston, Mass. Canada,

ISBN: 9780619216276, pp 86-104

Fagade T, Tryfonas T (2016) Security by Compliance? A Study of Insider Threat Implications for Nigerian Banks. In: Tryfonas $T$ (ed) Human aspects of information security, privacy, and trust. 4th International Conference, HAS 2016 , held as part of $\mathrm{HCl}$ International 2016, Toronto, ON, Canada, July 17-22, 2016 : proceedings, vol 9750 . Lecture notes in computer science Information systems and applications, incl. Internet/Web, and $\mathrm{HCl}$, vol 9750 . Springer, Cham.Heidelberg, ISBN: 978-3-319-39380-3, pp 128-139. doi: 10.1007/978-3-319-39381-0_12

Fuhrmann F, Scholl M, Edich D, Koppatz P, Scholl LR, Leiner KB, Ehrlich P (2017) Informationssicherheitsbewusstsein für den Berufseinstieg. Shaker, Aachen. ISBN: 978-3-8440-5466-8. doi: 10.2370/9783844054668

Gesellschaft für Informatik (2018) Unsere ethischen Leitlinien, Bonn
Göbel S (2017) Autorenumgebung für Serious Games. StoryTec: Eine Autorenumgebung und narrative Objekte für personalisierte Serious Games. Habilitationsschrift, TU Darmstadt

Haucke A, Pokoyski D (2018) Mea culpa. Schuld, Scham und Opferrolle bei Social Engineering. < <es > Zeitschrift fü Informationssicherheit(1):6-8

Helisch M, Pokoyski D (eds) (2009) Security awareness. Neue Wege zur erfolgreichen Mitarbeiter-Sensibilisierung, 1. Aufl. Edition kes. Vieweg + Teubner, Wiesbaden. ISBN: 978-3834806680

Huotari K, Hamari I (2017) A definition for gamification: Anchoring gamification in the service marketing literature. Electron Markets 27(1):21-31. doi: 10.1007/s12525-0150212-z

Institute of Play (2018) https://learncloud.rumie.org/collection/view/4801/institute-of-play. Accessed 14 Feb 2019

Kaspersky Lab (2018) Die DSGVO - mehr als nur ein Kontrollkästchen.

Khan B, Alghathbar KS, Nabi SI, Khan MK (2011) Effectiveness of information security awareness methods based on psychological theories. African Journal Business Management 5(26). doi: 10.5897/A|BM11.067

Kirlappos I, Beautement A, Sasse MA (2013) “Comply or Die" Is Dead: Long Live Security-Aware Principal Agents. In: Adams AA, Brenner M, Smith M (eds) Financial Cryptography and Data Security. FC 2013 Workshops, USEC and WAHC 2013, Okinawa, Japan, April 1, 2013, Revised Selected Papers, vol 7862. Lecture Notes in Computer Science / Security and Cryptology, v.7862. Springer Berlin Heidelberg, Berlin/Heidelberg, ISBN: 978-3-642-41319-3, pp 70-82. doi: 10.1007/978-3-642-41320-9_5

Kruger H, Drevin L, Steyn T (2007) Email Security Awareness - A Practical Assessment of Employee Behaviour. In: Futcher L, Dodge R (eds) Fifth World Conference on Information Security Education, vol 237. Springer US, Boston, MA, ISBN: 978-0-387-73268-8, pp 33-40

Pokoyski D (2009) Security Awareness: Von der Oldschool in die Next Generation - eine Einführung. In: Helisch M, Pokoyski D (eds) Security awareness. Neue Wege zur erfolgreichen Mitarbeiter-Sensibilisierung,

1. Aufl. Edition kes. Vieweg + Teubner, Wiesbaden, ISBN: 978-3834806680, pp 1-8

Scholl M (2018) Information Security Awareness in Public Administrations. In: Comite U (ed) Public

Management and Administration. InTech, ISBN: 978-1-78923-638-5. doi: 10.5772/intechopen.74572

Scholl M, Fuhrmann F, Pokoyski D (2016) Information Security Awareness 3.0 for Job Beginners. In: Quintela Varajão JE (ed). Proceedings of Conference on ENTERprise Information Systems/International Conference on Project MANagement/Conference on Health and Social Care Information Systems and Technologies, Porto, Portugal, ISBN: 978-989-97433-7-3, pp 433-436

Scholl M, Fuhrmann F, Scholl LR (2018) Scientific Knowledge of the Human Side of Information Security as a Basis for Sustainable Trainings in Organizational Practices. In: Bui T (ed) Proceedings of the 51 st Hawaii International Conference on System Sciences. Proceedings of the Annual Hawaii International Conference on System Sciences. Hawaii International Conference on System Sciences. doi: 10.24251/HICSS.2018.280

Stewart G, Lacey D (2012) Death by a thousand facts Information Management \& Computer Security 20(1):2938. doi: 10.1108/09685221211219182

Take Aware (2018) Take Aware. Die Security Awareness-Konferenz. https://www.take-aware.com/. Accessed 27 Nov 2018
Thales (2018) Schutz personenbezogener Daten - Warum die DSGVO nicht nur Geldbußen mit sich bringt. https:// go.thalesesecurity.com/DE-GDPR-Survey-Protecting-private-personal-data-Why-there-is-more-to-the-GDPR-thanjust-fines.html. Accessed 27 Nov 2018

Tsohou A, Karyda M, Kokolakis S, Kiountouzis E (2012) Analyzing trajectories of information security awareness. Info Technology \& People 25(3):327-352. doi: 10.1108/09593841211254358

\section{AUTHOR}

Prof. Dr. Margit Scholl

Business Informatics and Administration IT

Department Business, Computing, Law

Technische Hochschule Wildau

E-Mail for correspondence:

margit.scholl@th-wildau.de

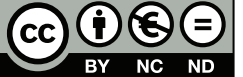

